\title{
Neonatal hypertension - a long-term pilot follow-up study
}

\author{
This article was published in the following Dove Press journal: \\ Research and Reports in Neonatology \\ 27 June 2013 \\ Number of times this article has been viewed
}

\author{
Tejasvi Chaudhari' \\ Michael C Falk ${ }^{2,3}$ \\ Rajeev Jyoti ${ }^{2,4}$ \\ Susan Arney ${ }^{5}$ \\ Wendy Burton ${ }^{5}$ \\ Alison L Kent ${ }^{1,2}$ \\ 'Department of Neonatology, \\ Canberra Hospital, Woden, ACT, \\ Australia; ${ }^{2}$ Australian National \\ University Medical School, Canberra, \\ ACT, Australia; ${ }^{3}$ Department of \\ Nephrology, ${ }^{4}$ Medical Imaging \\ Department, ${ }^{5}$ Centre for Newborn \\ Care, Canberra Hospital, Woden, ACT, \\ Australia
}

Background: Neonatal hypertension occurs in up to 3\% of neonates, more commonly in those admitted to neonatal intensive care. The aims of this study were to review renal function and renal volumes in children who had a history of neonatal hypertension.

Methods: Children with a history of neonatal hypertension from January 2001 to December 2008 were included in the study during 2011. Blood pressure, weight, height, and body mass index were recorded. Renal ultrasound with 3D volume, urine for electrolytes, albumin, $\beta 2$ microglobulin, and blood for electrolytes, urea, creatinine, calcium, phosphate, renin, and aldosterone were collected depending on parental consent.

Results: Of the 41 neonates with neonatal hypertension, eleven (27\%) were included in the study (six died; 24 moved interstate or declined involvement). One child (9\%) was still on antihypertensive medication and one was found to be hypertensive on review. This child had small volume kidneys and albuminuria. Three out of nine renal volume measurements were low (33\%) and two out of eleven had renal scarring (18\%). The six available renin/aldosterone results were normal.

Conclusion: This study suggests there are long-term renal and blood pressure implications for neonates with hypertension and ongoing surveillance of blood pressure and renal function should be performed throughout childhood and into early adulthood.

Keywords: neonate, hypertension, renal ultrasound, 3D

\section{Background}

Neonatal hypertension (HTN) was first described by Adelman in the 1970s. ${ }^{1}$ Since then, advances in neonatal practice have led to an increased awareness of hypertension in neonatal intensive care unit (NICU) graduates. Defining what is considered normal blood pressure (BP) in newborn infants is a complex task, as studies in both term and preterm infants have demonstrated that BP increases with both gestational and postconceptional age as well as with birth weight. ${ }^{2,3}$ A newborn infant is considered to have HTN if the systolic BP is above the 95th percentile of BP for infants of similar gestational or postconceptional age and size. ${ }^{4}$ For older infants and children, HTN is diagnosed if a systolic and/or diastolic pressure above the 95th percentile for age, gender, and height is found on three separate occasions. ${ }^{4}$

The incidence of HTN depends upon the population studied. In otherwise healthy term infants, HTN is uncommon. Among infants admitted to an NICU, the incidence ranges $0.7 \%-3 \% .^{5-8}$ In one retrospective Australian study of 2572 newborn infants, including patients admitted to the NICU, the incidence of HTN was $1.3 \%{ }^{8}$

Most cases of neonatal HTN are of renal origin, which includes mainly renovascular and renal parenchymal diseases. ${ }^{9,10}$ Umbilical artery catheter (UAC)-associated
Correspondence: Tejasvi Chaudhari Department of Neonatology, Canberra Hospital, PO Box II, Woden, 2606, ACT, Australia

Tel +6I 261747565

Fax $+6 \mid 262443112$

Email tejasvi.chaudhari@act.gov.au 
thromboembolism affecting the aorta and the renal arteries is the most common renovascular cause observed in the NICU. This was first described by Neal et al in $1972 .{ }^{11} \mathrm{He}$ demonstrated thrombus formation via aortography in 25 out of 31 infants at the time of catheter removal. It is assumed that thrombi are formed on the tip or surface of the catheter at the time of insertion of UAC as a result of disruption of the vascular endothelium of the umbilical artery. These thrombi can partially or completely occlude the abdominal aorta, decreasing renal perfusion. They may embolize to the renal artery, resulting in areas of infarction and increased renin release. ${ }^{12}$ Other vascular causes of neonatal HTN important to recognize include coarctation of the aorta, renal vein thrombosis, renal artery stenosis secondary to fibromuscular dysplasia or congenital rubella syndrome, and mechanical compression secondary to abdominal tumors. ${ }^{13,14}$ Renal parenchymal conditions associated with HTN comprise congenital disorders including autosomal dominant and autosomal recessive polycystic kidney diseases; ${ }^{15}$ obstructive uropathy in the form of congenital ureteropelvic junction obstruction; ${ }^{16,17}$ and acquired parenchymal diseases mainly due to acute tubular necrosis following perinatal asphyxia, sepsis, or other causes of inadequate perfusion. Neonatal HTN has also been found in association with bronchopulmonary dysplasia; ${ }^{18,19}$ medications such as dexamethasone, adrenergic agents, caffeine, pancuronium, and phenylephrine, ${ }^{20-22}$ endocrinological disorders such as congenital adrenal hyperplasia, ${ }^{23}$ and hyperaldosteronism. ${ }^{24}$

Diagnosis of neonatal HTN is important so that consideration is given to commencing treatment to prevent possible complications such as cardiac decompensation and possible risks for cardiovascular disease in later life. Some forms of neonatal HTN may persist beyond infancy. These generally include renal parenchymal disease such as polycystic kidneys, renal vein thrombosis, renal arterial stenosis, or coarctation of the aorta. ${ }^{13,15,22,25,26}$ Infants with idiopathic neonatal HTN may also have persistent HTN, but the little literature available suggests that this is generally short-lived. There is a paucity of literature describing the follow-up of children and young adults with a history of neonatal HTN and the clinical issue of when or if to discontinue antihypertensive medication. The aim of this study was to review renal function and renal volumes in children who had a history of neonatal HTN and determine whether they can have long-term renal and BP implications.

\section{Methods}

Neonates diagnosed with systemic HTN from January 2001 to December 2008 while inpatients in the NICU at Canberra
Hospital were included in the study. Systemic neonatal HTN was diagnosed when there were three separate measurements with a systolic or mean reading greater than the 95th percentile for gestational age. Data were obtained from a prospectively managed database of all infants admitted to the NICU and the hospital's computerized medical record system, which included neonatal follow-up clinics, nephrology clinics, and clinical notes of readmissions to the hospital. Information pertaining to HTN was derived from the database and patient medical records. Only children local to Australian Capital Territory (ACT) and surrounding New South Wales (NSW) regions were included in the study.

The study was approved by the ACT Human Research Ethics Committee. Parents of children who were diagnosed with HTN during their neonatal admission were sent an information package about the study including a consent form and all relevant material. Parents were then contacted by one of two research nurses for verbal consent to participate in the study. The written consent form was then completed at a face-to-face visit once the family agreed to participate in the study.

On the day of follow-up, each child had their height, weight, and body mass index (BMI) measured by the research nurse. Their BP was measured in the right upper arm. Three measurements were taken in a seated position using an appropriately sized cuff and oscillometric measurement (Vital Signs Monitor 300 Series; Welch Allyn, Rydalmere, NSW, Australia). Elevated BP was diagnosed if the systolic and mean BP were above the 95th percentile for their sex and height. ${ }^{4}$ An elevated BP reading obtained with an oscillometric device was repeated by using auscultation. Elevated BP was also confirmed on repeated visits before characterizing a child as having hypertension. Following parental consent, a renal ultrasound examination looking at size, volume, and any evidence of scarring was performed. A spot urine was collected (preferably first morning sample) and sent to the laboratory for urinary electrolytes, cell count, albumin/creatinine ratio, calcium/ creatinine ratio, $\beta 2$ microglobulin, and microalbumin. If consent was given, bloods were then taken for serum electrolytes, urea, creatinine, calcium, phosphate, renin, and aldosterone. If a child was found to be hypertensive or had ultrasound findings of concern, he/she was referred to a pediatrician or pediatric nephrologist for further management with information of their results also supplied to their primary caregivers.

\section{Three-dimensional ultrasound of the kidneys}

Children were scanned using an iU22 ultrasound machine (Philips, Amsterdam, The Netherlands). Renal volumes 
were assessed as per methodology previously reported. ${ }^{27}$ Three-dimensional images were obtained using a phased array split-crystal matrix 3- to 6-MHz 3D transducer by the sonographer immediately after 2D images. After visualization of maximum renal length in the longitudinal image, a posterior 3D sweep was performed (lateral to medial) and the raw data saved. Seven slices of each kidney were made perpendicular to the long axis of the kidney and slice thickness measured. The renal boundaries of each slice were traced in the axial reformation plane and individual slice areas were calculated by multiplying them with slice thickness. Images were then reconstructed by the ultrasound machine and renal volumes were measured via the integrated software using the stacked ellipses method (Figure 1). Measurements and data acquisition were performed by the same sonographers for consistency. Renal volumes were considered abnormal if they were more than two standard deviations below the norm. ${ }^{28}$

\section{Results}

During the study period, 41 neonates were diagnosed with systemic hypertension. Six (14.6\%) of these neonates died. Six $(14.6 \%)$ families had moved interstate while $18(44 \%)$ families declined involvement in the study. Eleven (26.8\%) children were available for follow-up.

The age of children ranged from 3 years to 9.5 years. Of the eleven patients, eight were born preterm ( $<37$ weeks); eight were male and three were female. Six patients had an umbilical arterial line inserted (Table 1). The umbilical line possibly contributed to the hypertension in all of these patients. Of the other five patients, three had renal tract anomalies including posterior urethral valves, renal agenesis, and renal pelvic dilatation; one patient had Turner Syndrome; and one patient had

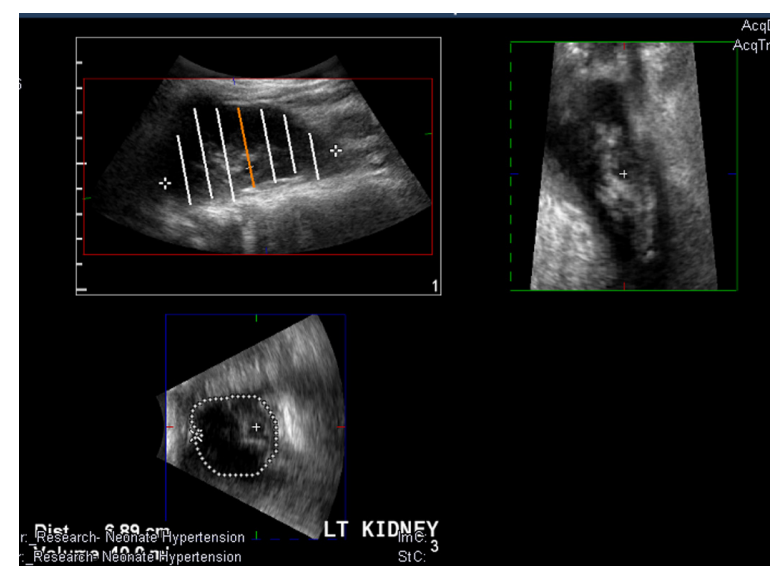

Figure I 64-month-old child with hypertension. This matrix array transducer 3D sonography image was used to obtain measurements for the calculation of renal volume. idiopathic hypertension. BP measurements were available for all children. Only one child (case 5 - see Table 1) had an elevated BP. $^{4} \mathrm{He}$ was a 30 -week preterm neonate admitted to the NICU for prematurity and respiratory distress. He had umbilical lines inserted whilst in the NICU. His renal ultrasound was normal during the admission. This patient had mild albuminuria and a small echogenic focus in the left kidney possibly resembling an angiomyolipoma. The renal volumes were almost two standard deviations below normal for the child's weight. ${ }^{28} \mathrm{He}$ continued to have elevated BP upon follow-up a few months later. He was referred to a pediatric nephrologist for ongoing management. One child (case 1) continued on antihypertensive medication (labetalol) from the neonatal period and his BP was within the normal range. This child had posterior urethral valves fulgurated during the neonatal period and ongoing bilateral vesicoureteric reflux. Thus two cases (18\%) were considered to have ongoing hypertension.

Bloods were obtained from eight (73\%) patients. Of these, six had renin and aldosterone results (sample insufficient in two patients) which were all within the normal range (including the child diagnosed with hypertension). Serum electrolytes, calcium, phosphate, creatinine, and estimated glomerular filtration rate levels were normal in all eight patients. Urine was obtained in eight patients. Only one patient (case 5) showed evidence of albuminuria. Urine microglobulin was measured in six patients, all of which were normal.

A renal ultrasound was obtained in all patients, with nine having volume assessments available. One patient (case 1) had bilateral prominent pelvicalyceal systems from previous reflux. One patient (case 3 ) had a congenital solitary right kidney. One patient (case 5) had an echogenicity at the junction of the upper and midpoles of the left kidney resembling an angiomyolipoma. Two patients (cases 9 and 10) had evidence of scarring, possibly from previous urinary tract infections (UTI). None of these patients had a UTI during the neonatal period. Two out of nine (22\%) patients had abnormal renal volume measurements (cases 9 and 11). Case 9 had previous UTIs while case 11 had CHARGE (coloboma of the eye, heart defects, atresia of the nasal choanae, retardation of growth and/or development, genital and/or urinary abnormalities, and ear abnormalities and deafness) association.

\section{Discussion}

There have been very few studies following neonates with systemic hypertension into childhood or early adulthood. Friedman and Hustead reported on a population of preterm infants, including 17 hypertensive babies, for a period of 6-42 months after discharge. ${ }^{29}$ A cause for the HTN 


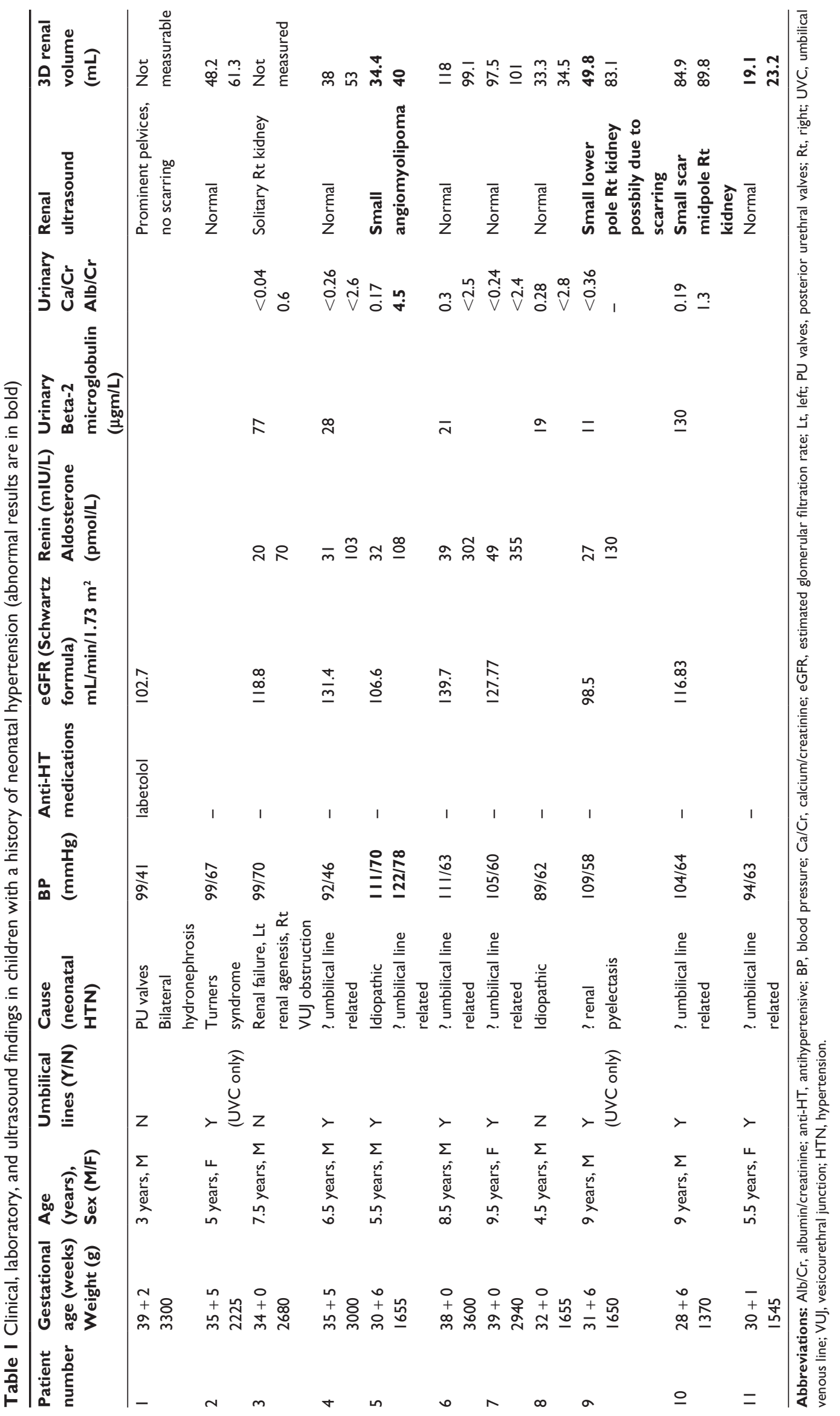


was identified in five infants (29\%); the remainder were considered to have idiopathic HTN. All were normotensive by 2 years corrected age and were able to discontinue their medications. Adelman et al reported on 12 neonates with renovascular HTN who were followed for a mean of 5.75 years. BP normalized in all the patients and remained so when medications were discontinued, although there were persistent abnormalities in renal size and function. ${ }^{30}$ The findings of note in our study were two out of eleven children $(18 \%)$ continuing to have elevated BP with a significant proportion of patients having persistent abnormalities of their kidneys.

To the best of our knowledge, this is the first study to have followed children up to 10 years of age looking for evidence of renal involvement as a consequence or cause for persistent HTN. We found that two out of eleven children (18.2\%) had persistent HTN. While one of them was already on hypertensive medications, the other had persistent HTN which was not detected until follow-up with this study. This patient had albuminuria, small-sized kidneys on 3D volume, and a possible small angiomyolipoma in one of the kidneys. The renin aldosterone levels were normal in this patient. Though there was evidence of scarring on renal ultrasound in two other children, they were not hypertensive. While the etiology of hypertension in the child with bilateral reflux can be attributed to his kidneys, the cause of persistently elevated $\mathrm{BP}$ in the other child is unclear. Although this child had an umbilical arterial line inserted during the neonatal period, there was no evidence of focal infarct/ischemia causing renal injury. However, no radionuclide scan or doppler studies were done during the neonatal period, hence this could not be completely ruled out. The small kidneys in this child could also be due to congenital oligonephronia as a result of prematurity and/or nephrotoxic drugs. ${ }^{31}$ It is also possible that the neonatal hypertension itself caused nephron loss and small kidneys. Reduced glomerular numbers and nephron mass have been well-documented in adult hypertension studies. $^{32}$

From the available literature, in most infants, the HTN related to umbilical arterial catheter resolves with time..$^{30,33}$ Since this is the most common cause of neonatal hypertension, the overall long-term prognosis is usually favorable in such infants. However, some forms of neonatal HTN, especially renal parenchymal and vascular conditions, may persist and cause further renal and cardiovascular compromise. ${ }^{22}$ This may also hold true in the case of preterm infants. Preterm infants may lack the normal number of glomeruli seen in term infants as glomerulogenesis is incomplete at the time of delivery and ongoing glomerulogenesis may be affected by a number of postnatal insults including poor nutrition and nephrotoxic medications. ${ }^{31}$ Faa et al biopsied kidneys in 23 subjects (eight fetuses, 12 premature infants, and three term infants) at autopsy. They found that glomerulogenesis was markedly decreased in all preterm infants compared to term newborns. Marked interindividual variation was also found in the number of nephrons observed in preterm infants even at the same gestational age and weight, suggesting a role of drugs or other factors impairing nephrogenesis. ${ }^{34}$ Thus prematurity and low birth weight may cause persistent oligonephronia which has been described as a known risk factor for developing HTN in adulthood. ${ }^{31,35}$ Small nephron size leads to reduced glomerular filtration area which in turn may cause reduced sodium excretion, and fluid and sodium retention, and subsequent HTN. ${ }^{35,36}$ Thus, even normotensive preterm neonates are at increased risk compared to term infants for the development of HTN later in life. ${ }^{36}$

Renal volume and growth are important parameters for evaluating and monitoring several renal conditions including renal transplant recipients, chronic renal failure, vesicoureteric reflux, and hypertension following renal arterial stenosis. ${ }^{37,38}$ A change in measurement from one examination to another may indicate presence or progression of the disease. Hence, it is important that the technique used for the measurements is accurate and reproducible. Renal volume measurements using ultrasound are comparable to those using computed tomography/ magnetic resonance imaging. ${ }^{28}$ The advantages of ultrasound include the fact that it is noninvasive, quick, cheap, involves no radiation exposure, and is widely available. Standard nomograms exist for comparison and previous studies have shown good correlation with age, body weight, and renal function. ${ }^{39-41}$ Serial measurements of renal volume in neonates and children with HTN could be a good adjunct to other investigations in studying the etiology and monitoring progress of renal compromise.

\section{Conclusion}

This study suggests that children who have had HTN in the neonatal period are at increased risk of ongoing HTN and renal compromise, indicating that these children should have ongoing monitoring of their BP and renal function throughout childhood and into early adulthood. Three-dimensional ultrasound imaging is a novel and appropriate investigation in this population. We acknowledge the limited subject number in our study due to difficulty in follow-up. However, our study detected raised BP and renal abnormalities in a number of patients. Further large, long-term follow-up studies monitoring $\mathrm{BP}$ and renal function of those with 
a history of neonatal HTN into late childhood and early adulthood are required.

\section{Acknowledgments}

We would like to thank the medical records department for providing access to medical records and the parents and children involved in the study. Financial support for this project was provided by the Canberra Hospital Private Practice Fund.

\section{Disclosure}

The authors report no conflicts of interest in this work.

\section{References}

1. Adelman RD. Neonatal hypertension. Pediatr Clin North Am. 1978;25: 99-110.

2. Georgieff MK, Mills MM, Gomez-Marin O, Sinaiko AR. Rate of change of blood pressure in premature and full-term infants from birth to 4 months. Pediatr Nephrol. 1996;10:152-155.

3. Zubrow AB, Hulman S, Kushner H, Falkner B. Determinants of blood pressure in infants admitted to neonatal intensive care units: a prospective multicenter study. J Perinatol. 1995;15:470-479.

4. National High Pressure Education Program Working Group on High Blood Pressure in Children and Adolescents. The fourth report on the diagnosis, evaluation, and treatment of high blood pressure in children and adolescents. National Heart, Lung, and Blood Institute, Bethesda, Maryland. Pediatrics. 2004;114:555-557.

5. Skalina ME, Kliegman RM, Fanaroff AA. Epidemiology and management of severe symptomatic neonatal hypertension. Am J Perinatol. 1986;3:235-239.

6. Singh HP, Hurley RM, Myers TF. Neonatal hypertension. Incidence and risk factors. Am J Hypertens. 1992;5:51-55.

7. Buchi KF, Siegler RL. Hypertension in the first month of life. J Hypertens. 1986;4:525-528.

8. Seliem WA, Falk MC, Shadbolt B, Kent AL. Antenatal and postnatal risk factors for neonatal hypertension and infant follow-up. Pediatr Nephrol. 2007;22:2081-2087.

9. Dillon MJ. Secondary forms of hypertension in children. In: Portman RJ, Sorof JM, Inglefinger IR, editors. Pediatric hypertension. Totowa, Humana Press; 2004:159-179.

10. Arar MY, Hogg RJ, Arant BS Jr, Seikaly MG. Etiology of sustained hypertension in children in southwestern United States. Pediatr Nephrol. 1994;8:186-189.

11. Neal WA, Reynolds JW. Jarvis CW, Williams HJ. Umbilical artery catheterisation: demonstration of arterial thrombosis by aortography. Pediatrics. 1972;50:6-13.

12. Boo NY, Wong NC, Zulkifli SS, Lye MS. Risk factors associated with umbilical vascular catheter-associated thrombosis in newborn infants. J Paediatr Child Health. 1999;35:460-465.

13. Mocan H, Beattie TJ, Murphy AV. Renal venous thrombosis in infancy: long-term follow-up. Pediatr Nephrol. 1991;5:45-49.

14. Hegde S, Wright C, Shenoy M, Moghal NE, Coulthard MG. Renovascular hypertension commencing during fetal life. Arch Dis Child Fetal Neonatal Ed. 2007;92:F301-F304.

15. Guay-Woodford LM, Desmond RA. Autosomal recessive polycystic kidney disease: the clinical experience in North America. Pediatrics. 2003;111:1072-1080.

16. Munoz AI, Baralt JF, Melendez MT. Arterial hypertension in infants with hydronephrosis. Report of six cases. Am J Dis Child. 1977;131:38-40.

17. Braren V, West JC Jr, Boerth RC, Harmon CM. Management of children with hypertension from reflux or obstructive nephropathy. Urology. 1988;32:228-234.
18. Abman SH, Warady BA, Lum G, Koops BL. Systemic hypertension in infants with bronchopulmonary dysplasia. J Pediatr. 1984;104: 928-931.

19. Alagappan A, Malloy MH. Systemic hypertension in very low-birth weight infants with bronchopulmonary dysplasia: incidence and risk factors. Am J Perinatol. 1998;15:3-8.

20. Greenough A, Emery EF, Gamsu HR. Dexamethasone and hypertension in preterm infants. Eur J Pediatr. 1992;151:134-135.

21. Greher M, Hartmann T, Winkler M, Zimpfer M, Crabnor CM. Hypertension and pulmonary edema associated with subconjunctival phenylephrine in a 2-month old child during cataract extraction. Anesthesiology. 1998;88:1394-1396.

22. Dionne JM, Abitbol CL, Flynn JT. Hypertension in infancy: diagnosis, management and outcome. Pediatr Nephrol. 2012;27(1):17-32.

23. White PC. Inherited forms of mineralocorticoid hypertension. Hypertension. 1996;28:927-936.

24. Pozzan GB, Armanini D, Cecchetto G, et al. Hypertensive cardiomegaly caused by an aldosterone-secreting adenoma in a newborn. J Endocrinol Invest. 1997;20:86-89.

25. Roy S, Dillon MJ, Trompeter RS, Barratt TM. Autosomal recessive polycystic kidney disease: long-term outcome of neonatal survivors. Pediatr Nephrol. 1997;11:302-306.

26. O'Sullivan JJ, Derrick G, Darnell R. Prevalence of hypertension in children after early repair of coarctation of the aorta: a cohort study using casual and 24 hour blood pressure measurement. Heart. 2002;88:163-166.

27. Kent AL, Jyoti R, Robertson C, et al. Are renal volumes measured by magnetic resonance imaging and three-dimensional ultrasound in the term neonate comparable? Pediatr Nephrol. 2010;25(5):913-918.

28. Fritz GA, Riccabona M, Bohdal G, Quehenberger F. [Accuracy of renal volume assessment in children by three-dimensional sonography.] Rofo. 2003;175(4):540-546. German.

29. Friedman AL, Hustead VA. Hypertension in babies following discharge from a neonatal intensive care unit. A 3-year follow-up. Pediatr Nephrol. 1987;1(1):30-34.

30. Adelman RD. Long-term follow-up of neonatal renovascular hypertension. Pediatr Nephrol. 1987;1(1):35-41.

31. Rodríguez MM, Gómez AH, Abitbol CL, Chandar JJ, Duara S, Zilleruelo GE. Histomorphometric analysis of postnatal glomerulogenesis in extremely preterm infants. Pediatr Dev Pathol. 2004;7:17-25.

32. Keller G,Zimmer G, Mall G, RitzE, Amann K. Nephron number in patients with primary hypertension. $N$ Engl J Med. 2003;348:101-108.

33. Caplan MS, Cohn RA, Langman CB, Conway JA, Shkolnik A, Brouillette RT . Favorable outcome of neonatal aortic thrombosis and renovascular hypertension. J Pediatr. 1989;115(2):291-295.

34. Faa G, Gerosa C, Fanni D, et al. Marked interindividual variability in renal maturation of preterm infants: lessons from autopsy. J Matern Fetal Neonatal Med. 2010;23 Suppl 3:129-133.

35. Mackenzie HS, Lawler EV, Brenner BM. Congenital olionephropathy the fetal flaw in essential hypertension. Kidney Int Suppl. 1996;55: S30-S34.

36. Brenner BM, Garcia DL, Anderson S. Glomeruli and blood pressure. Less of one, more the other? Am J Hypertens. 1988;1:335-347.

37. Gong IH, Hwang J, Choi DK, et al. Relationship among total kidney volume, renal function and age. J Urol. 2012;187(1):344-349.

38. Moorthy HK, Venugopal P. Measurement of renal dimensions in vivo: a critical appraisal. Indian J Urol. 2011;27:169-175.

39. Dixit PK, Sahai SB, Rath B, Garg A, Chowdhury V. Norms for renal parenchymal volume in Indian children. Indian Pediatr. 1994;31(9): 1059-1064.

40. Oswald J, Schwentner C, Lunacek A, Deibl M, Bartsch G, Radmayr C. Age and lean body weight related growth curves of kidneys using real-time 3-dimensional ultrasound in pediatric urology. J Urol. 2004;172(5 Pt 1):1991-1994.

41. Kim HC, Yang DM, Jin W, Lee SH. Relation between total renal volume and renal function: usefulness of $3 \mathrm{D}$ sonographic measurements with a matrix array transducer. AJR Am J Roentgenol. 2010;194(2):W186-W192. 
Research and Reports in Neonatology

Dovepress

\section{Publish your work in this journal}

Research and Reports in Neonatology is an international, peer-reviewed, open access journal publishing original research, reports, editorials, reviews and commentaries on neonatal health. The manuscript management system is completely online and includes a very quick and fair

peer-review system. Visit http://www.dovepress.com/testimonials.php to read real quotes from published authors. 